\title{
General framework for revising class A3 refrigerant charge limits - a discussion
}

\author{
D. Colbourne ${ }^{(a)}$ * K. O. Suen ${ }^{(b)}$, T-X Li, ${ }^{(c)}$, I. Vince ${ }^{(d)}$, A. Vonsild ${ }^{(e)}$ \\ (a) Re-phridge, c/o HEAT GmbH, Seilerbahnweg 14, 61462 Königstein, Germany \\ (b) University College London, Gower Street, London, WC1E 6BT, UK \\ (c) Sun Yat Sen University, Guangzhou, Peoples Republic of China \\ (d) ASK Consultants, Beckenham, United Kingdom \\ (e) Vonsild Consulting, Vejle, Denmark \\ (* corresponding author)
}

\section{Highlights}

- Validity and form of current flammable refrigerant charge limits have been examined.

- Current format and formulae of charge limits do not adequately account for flammability risk.

- Improved approach accounts for ways by which the formation of flammable mixtures can be minimised.

- Propose to eliminate upper charge limits whilst retaining allowable charge limits.

\begin{abstract}
Currently, industry and governmental entities are increasingly concerned with the restrictive controls on flammable refrigerant - particularly class A3 - charge limits, within safety standards. Since A3 refrigerants, such as R290 and R1270, are in many respects considered as desirable refrigerants to help resolve the global warming problem associated with other options (such as HFCs), safety standards should be formulated so that A3 refrigerant could be applied more widely than permitted today. An analysis of current standards reveals the extent to which A3 refrigerants currently can be applied. Further analysis of these and standards from other sectors help identify concepts and protective measures that can be applied to extend equipment across a range of larger cooling and heating capacities. The objective is to discuss how charge limits could be revised to enable a wider application of A3 refrigerants, with respect to safety regulations and associated implications, concepts and approaches available in published literature.
\end{abstract}

Keywords: flammable refrigerants, hydrocarbon refrigerants, safety, charge limits, safety standards

\section{Nomenclature}

$\begin{array}{ll}\text { ACHP } & \text { Air Conditioner and Heat Pump } \\ \text { ACL } & \text { Allowable Charge Limit } \\ \text { ATEX } & \text { Atmospheres Explosibles } \\ \text { CEN } & \text { European Committee for Standardisation } \\ \text { CL } & \text { Charge Limit } \\ \text { EU } & \text { European Union } \\ \text { HC } & \text { Hydrocarbon } \\ \text { HFC } & \text { Hydrofluorocarbon } \\ \text { HoC } & \text { Heat of Combustion } \\ \text { HSE } & \text { Health and Safety Executive (UK governmental safety regulator) } \\ \text { IEC } & \text { International Electrotechnical Commission } \\ \text { ISO } & \text { International Organisation for Standardisation } \\ \text { LFL } & \text { Lower Flammability Limit } \\ \text { LIFE FRONT } & \text { Flammable Refrigerant Options for Natural Technologies of the EU LIFE programme } \\ \text { NSB } & \text { National Standardisation Body } \\ \text { RACHP } & \text { Refrigeration, Air-Conditioning and Heat Pump } \\ \text { SOI } & \text { Source of Ignition }\end{array}$




\section{Introduction}

As the refrigeration, air conditioning and heat pump (RACHP) industry is increasingly channelled into using environmentally benign refrigerants, there is more attention paid to the use of hydrocarbons (HCs), such as R290 (propane), R1270 (propene) and R600a (isobutane). Since they have higher flammability (class "A3" under ISO 817), the quantities of charge allowed within occupied spaces tend to be constrained (IIF-IIR, 2017). Historically, A3 charge limits (CLs) were put in place without much technical rationale. To promote the wider use of them in RACHP systems and to respond to regional and international legislation on phasingdown HFCs, CLs need to be increased, while avoiding any significant increase in flammability risk. This warrants a closer examination on how restrictive the current CLs are and whether it is feasible to raise those limits.

Many recent studies have concluded that the present CLs are unnecessarily tight and further work could contribute to improving the situation. These include the EU LIFE Front project (Zolcer Skačanová et al, 2018) and UNEP TEAP Task Force report (UNEP, 2017) under the Montreal Protocol. Within this context, it is useful to clarify the web of standards and supporting legislation around the world. Currently, almost all safety standards are developed within a small number of international bodies. Broadly, these include the International Organisation for Standardisation (ISO) and International Electrotechnical Commission (IEC), and at the regional European level, the European Committee for Standardisation (CEN) and European Committee for Electrotechnical Standardisation (CENELEC). Their members that include national standards bodies (NSBs) tend to adopt and publish these standards nationally either "as is" or with typically minor modifications to suit any local legislation.

The legal implications associated with these standards differ widely. In some countries, the NSB may be a government entity and the standard may have status equivalent to a national regulation. Whilst in others, these safety standards are simply seen as informatory or best practice guidelines. The status of these standards usually falls somewhere in between these two extremes, i.e., intended to hold the standing of "ought to use", but not legally mandatory. Within Europe, standards are often "harmonised" with European directives, whereby they imply conformity to legislation; generally, they provide a practical interpretation of the applicable health and safety legislation (EU Blue Guide, 2016). Thus, the two options open to manufacturers are to (a) comply with the legislation directly and (b) conform to a harmonised standard; the latter is normally chosen since it is more explicit, quantifiable and there is less room for subjectivity. Furthermore, there are substantially greater cost implications associated with demonstrating compliance with the regulation(s), compared to following a harmonised standard.

Almost all RACHP safety standards are continually under revision, not only for CLs but also with respect to mechanical, pressure and electrical safety, etc.

Critical to the present discussion is that these safety standards tend to be drafted by a relatively small number of individuals, nominated by NSBs. Considering that the topics handled by these standards are so wideranging, it is difficult to find sufficient numbers of specialists in any one of the key fields. Furthermore, since the process of standards development is essentially voluntary and functions under the principles of consensus, the process - as determined by each technical committee can be rather drawn-out and extremely costly (due to the number of regional or international meetings and the need to carry out internal $R \& D$, etc.).

IEC and ISO publish guidelines to assist with the drafting of standards. IEC Guide 104 (2019) advises on the organisation and arrangement of safety standards. ISO/IEC Guide 51 (2014) provides an overview on how safety standards should be drafted, with a particular focus on identifying evaluation of risks and assessing effectiveness of protective measures. IEC Guide 116 (2018) provides more detailed guidance for development of the requirements, considering both evaluation of the proposed measures and assessment of 
their reliability. Whilst these do not deal with CLs specifically, they provide a useful context for developing new rules.

The objective of this paper is to discuss how flammable refrigerant CLs could be revised within current RACHP safety standards to enable a wider application of A3 refrigerants, by analysing the safety regulations and the associated implications, concepts and approaches available in published literature. A framework for integrating alternative means of CL determination into safety standards is presented.

An important footnote to this entire discussion is that "safety" cannot be considered in isolation. The UK Health and Safety Executive (HSE) policy document (HSE R2P2, 2001) points out that quality of life is also a fundamental consideration and so the benefits of a particular technology (such as a near zero GWP, comparatively higher efficiency refrigerants) that can potentially introduce new hazards (i.e., flammability) should be weighed up against the detriment of competing refrigerant technologies (e.g., high GWP and often lower efficiency). As an example, whilst flammable refrigerants may pose an immediate hazard to persons and property, emissions of fluorinated refrigerants could become responsible for some 15,000 global warming related fatalities, i.e., as a proportion of the warming impact from fluorinated refrigerants of the anticipated quarter of a million expected, in the year 2030 (WMO, 2014). Obviously, these numbers are approximate and it is not possible to accurately assign them to fluorinated refrigerants in isolation, but nevertheless it helps highlight the scale of the issue, where the number dwarfs that which could be attributed to flammability risks arising from the use of $\mathrm{A} 3$ refrigerants.

\section{Current RACHP standards and associated CLs}

The scope of the present work is limited to relatively "small" systems, with a cooling or heating capacity of up to $25 \mathrm{~kW}$, both applied to European and international cases. These include residential and light commercial air conditioning, commercial refrigeration such as display and food storage cabinets, small coldroom units, and domestic and small commercial heat pumps. General characteristics of such systems can be found in the UNEP RTOC report (2018). RACHP safety standards of concern are primarily ISO 5149, IEC 60335-2-40 and IEC 60335-2-89 at International level and EN 378 in Europe, and their CLs are shown in Table 1 along with the relevant equipment and application sectors. There are two forms of CL, as termed here $^{1}$ :

- "upper charge" refers to the highest absolute mass of refrigerant permitted in any one refrigerant circuit, irrespective of room size and is generally a function of access category (such as general/public space, supervised space, or authorised space, e.g., as in EN 378);

- "allowable charge" is the value that is determined according to the dimensions of the space within which the system is installed, but which cannot exceed the upper charge.

Allowable charge limits (ACLs) do not apply to systems in the open air, as they effectively are of infinite dimensions. Similarly, for approaches that exhaust leaked refrigerant to the outside and intended to avoid accumulation of refrigerant within the enclosed space, the ACL is essentially redundant. Currently, the "ventilated enclosure" concept - that is offered in both IEC 60335-2-40 and EN 378 - permits an upper charge limit (UCL), but also prescribes additional measures, including gas detection, mechanical ventilation and a certain air tightness of the enclosure. Table 1 summarises the main CLs across the various standards and according to approximate equipment categories.

\footnotetext{
${ }^{1}$ Terminology differs across standards, so these phrases have been adopted here for brevity.
} 
Table 1: Refrigerant charge limits for HCs according to safety standards for RACHP systems

\begin{tabular}{|l|c|c|c|c|}
\hline \multirow{2}{*}{ Example equipment/application } & \multicolumn{2}{|c|}{ IEC 60335-2-24, -40,-89 (Vertical) } & ISO 5149, EN 378 (Horizontal/group) \\
\cline { 2 - 5 } & Upper CL (UCL) & $\begin{array}{c}\text { Allowable CL } \\
\text { (ACL) }\end{array}$ & Upper CL (UCL) & $\begin{array}{c}\text { Allowable CL } \\
\text { (ACL) }\end{array}$ \\
\hline Domestic refrigeration & $0.15 \mathrm{~kg}$ & $0.15 \mathrm{~kg}$ & $\mathrm{n} / \mathrm{a}$ & $\mathrm{n} / \mathrm{a}$ \\
\hline Commercial refrigeration & $0.5 \mathrm{~kg}$ & $0.01 \times V_{\mathrm{rm}}$ & $1.5 \mathrm{~kg}$ & $0.008 \times V_{\mathrm{rm}}$ \\
\hline $\begin{array}{l}\text { Systems in machinery rooms or } \\
\text { open air }\end{array}$ & $\mathrm{n} / \mathrm{a}$ & $\mathrm{n} / \mathrm{a}$ & $\begin{array}{c}2.5,10,25 \mathrm{~kg}, \mathrm{no} \\
\text { limit }\end{array}$ & $0.008 \times V_{\mathrm{rm}}$ \\
\hline ACHP: Small self-contained & $0.3 \mathrm{~kg}$ & $0.01 \times V_{\mathrm{rm}}$ & $0.3 \mathrm{~kg}$ & $0.01 \times V_{\mathrm{rm}}$ \\
\hline ACHP: Other packaged \& split & $1 \mathrm{~kg}$ & $0.04 \times h \times A_{\mathrm{rm}}^{0.5}$ & $1.0 \mathrm{~kg} / 1.5 \mathrm{~kg}$ & $0.04 \times h \times A_{\mathrm{rm}}^{0.5}$ \\
\hline ACHP: Within vented enclosure & $1 \mathrm{~kg}, 5 \mathrm{~kg}$ & $\mathrm{n} / \mathrm{a}$ & $5 \mathrm{~kg}$ & $\mathrm{n} / \mathrm{a}$ \\
\hline ACHP: In open air & \multicolumn{2}{|c|}{$1 \mathrm{~kg}, 5 \mathrm{~kg}$} & $1.5 \mathrm{~kg}, 5 \mathrm{~kg}, 10 \mathrm{~kg}, 25 \mathrm{~kg}, \mathrm{no} \mathrm{limit}$ \\
\hline
\end{tabular}

where: $V_{\text {rm }}=$ room volume $\left(\mathrm{m}^{3}\right) ; A_{\mathrm{rm}}=$ room floor area $\left(\mathrm{m}^{2}\right)$ and $h=$ unit installation height $(\mathrm{m})$.

"n/a" means not applicable.

Note: for brevity, some formulae have been simplified based on a nominal HC lower flammability limit of $40 \mathrm{~g} \mathrm{~m}^{-3}$. Two or more values within a cell refer to different access categories.

All CLs apply to individual refrigerating circuits only.

There are two categories of standards. So-called "vertical" standards are theoretically aimed at particular types of factory-produced serial products, although in actual fact they often cover a huge range of products and equipment. These vertical standards are generally issued by IEC, whilst "horizontal" or "group" standards are intended to cover an entire sector, ranging from one-off units to mass-produced systems. These horizontal/group standards address basic principles and classifications, system design and construction, installation areas and system handling by workers. Historically and at present the ISO, IEC and EN standards are drafted separately and subject to different approval processes, but are broadly consistent with each other.

In addition to these "product" or "equipment" standards, there are peripheral standards, which do not specifically address CLs, but provide supplemental information and guidance with regards to safe application of system components such as valves, design of piping, electrics, safety characteristics of refrigerants, knowledge requirements for technicians and engineers, etc.

Furthermore, in parallel with the RACHP standards for flammable refrigerants, there are a host of safety standards aimed at application of flammable gases (and dust), that have been under continual development for decades. These standards (e.g., within the IEC 60079-series) include basic principles for explosion protection, identifying areas that could be potentially flammable/explosive, test methods for determining flammable characteristics of fluids, eliminating potential sources of ignition (SOI) and so on. From a European perspective, most of these standards are harmonised to the Atmospheres Explosibles (ATEX) directives; both for products and workplace. It is noteworthy that none of these standards (or indeed the ATEX directives) impose any limits of quantities of flammables gases for any situation or location.

Across European and International standards, the degree of stringency of CLs differs according to the refrigerant safety classification, familiarity and competence of occupants, and the location of the refrigerantcontaining system parts in relation to those occupants. Increasing competence of personnel associated with the RACHP system permits more generous CLs, assuming the occupants would have a good knowledge of how to react to a refrigerant release. Similarly, systems located indoors are subject to stricter CLs on account of dilution of a release being more difficult to achieve than with an outdoor situation. Absolute values differ across the various RACHP standards, classes of RACHP equipment and refrigerant types.

Amongst the requirements of these standards, there are no room size restrictions for indoor RACHP systems where the refrigerant charge is less than or equal to four times the lower flammability limit (LFL), (" $4 \times$ LFL"), which corresponds to around $150 \mathrm{~g}$ for R290. As seen in Table 1, there are several incremental upper 
charge limits, ranging from $0.15 \mathrm{~kg}$ up to "no limit". This complex structure has proven to pose a significant barrier to the application of A3 refrigerants since practitioner must have knowledge of each limit for any given set of circumstances.

\section{Implications of current CLs}

Use of CLs is in principle intended to preclude the formation of "large" volumes of a flammable mixture in the event of a leak. To determine a CL, a large number of assumptions are required, relating to system/equipment characteristics, nature of leaks, conditions within the room and so on. These have in many cases led to significant constraints for applicability of A3 refrigerants.

\section{$3.10 .15 \mathrm{~kg}$ limit}

The domestic refrigeration standard IEC 60335-2-24 which was the first to include provision for using A3 refrigerants in 1992 (as EN 335-2-24); this edition permitted up to $0.15 \mathrm{~kg}$ of "flammable refrigerant" (originally intended for R600a) in systems in any location, irrespective of room size. This approach has since migrated to other safety standards.

The origin of the $0.15 \mathrm{~kg}$ limit was based on a simple calculation for HCs assuming the "smallest likely" kitchen, and a fraction of the LFL (i.e., $20 \%$ of the LFL) times the kitchen volume; $\left(20 \% \times 0.04 \mathrm{~kg} \mathrm{~m}^{-3}\right) \times$ $2.5 \mathrm{~m} \times 7 \mathrm{~m}^{2}=$ approx. $0.15 \mathrm{~kg}$. Over the following years, " $150 \mathrm{~g}$ " has become the assumed boundary between "safe" and "unsafe", and has also been used as a foundation for subsequent derivations of CLs for other flammable refrigerants. For instance, in order to apply a limit to charges of non-A3 refrigerants, 0.15 $\mathrm{kg}$ was divided by the LFL of R290 $\left(0.038 \mathrm{~kg} \mathrm{~m}^{-3}\right)$ to yield a constant of approximately $4\left(\mathrm{~m}^{3}\right)$, which may then be applied to other refrigerants with different LFLs, to provide an LFL-equivalent mass. This then led to the expression " $\mathrm{m} 1$ " (= $4 \times \mathrm{LFL})$ in various standards. It was further extended to " $\mathrm{m} 2$ " to equate to $1 \mathrm{~kg}$ $\mathrm{R} 290(=26 \times \mathrm{LFL})$ and " $\mathrm{m} 3$ " for $5 \mathrm{~kg}(=130 \times \mathrm{LFL})$, although the value of the constants has then been subject to gradual increases for class A2L refrigerants.

Whilst amongst RACHP safety standards $0.15 \mathrm{~kg}$ has become a presumed safety boundary, analyses of appliances with a fixed charge has shown that one design may be lower risk by a factor of 1,000 or 10,000 , than another with a far poorer design (e.g., Colbourne and Espersen, 2013). This highlights the fact that flammability risk of RACHP equipment is far from dependent upon the charge amount, and that introduction of protective measures (discussed later) could have a far greater influence.

The fact that domestic refrigerators have proved to be "safe" (in terms of about 1000 million appliances in use with R600a globally but with only a handful of accidents attributed to ignition of leaked refrigerant) is probably more to do with the very low likelihood of leakage from the factory-sealed systems, due to extremely thorough quality control in place with large manufacturers. By comparison, systems using much larger " $\mathrm{m} 1$ " of an A2L refrigerant (e.g., $4 \times 0.3 \mathrm{~kg} \mathrm{~m}^{-3}=1.8 \mathrm{~kg}$ ) can comprise detachable connections and hundreds of other joints, thus increasing the likelihood of leakage. Thus, it may not be appropriate to transpose charge limits in this way for other refrigerants.

Nevertheless, the default $150 \mathrm{~g}$ limit has had the impact of proliferating the belief amongst the RACHP industry that a charge size of $<150 \mathrm{~g}$ (or " $\mathrm{m} 1$ ") "is safe". Until recently IEC 60335-2-89 contained the same $0.15 \mathrm{~kg}$ limit for all appliances (including for A2 and A2L refrigerants), whilst since June 2019, a revision was published to increase the A3 UCL from $0.15 \mathrm{~kg}$ to $0.50 \mathrm{~kg}$ (hydrocarbons21.com, 2019). CLs for A3s in IEC 60335-2-40, EN 378 and ISO 5149 vary somewhat.

\subsection{Limits for air conditioners and heat pumps/ "comfort" applications}

Within IEC 60335-2-40, EN 378 and ISO 5149, there is an ACL formula for systems using more than 0.15 $\mathrm{kg}$ of A3, that was originally inserted into the 2003 edition of IEC 60335-2-40. The CL is expressed as a function of LFL (to the power 1.25), unit installation height $\left(h_{0}\right)$ and the square root of the room area $\left(A_{r m}^{0.5}\right)$. Within the standard, specific values of $h_{0}$, measured from the floor to the base of the unit, were listed for floor-mounted units $(0.6 \mathrm{~m})$, window units $(1.0 \mathrm{~m})$, wall units $(1.8 \mathrm{~m})$ and ceiling mounted units $(2.2 \mathrm{~m})$. 
Their ACLs calculated using this formula are shown as the curves in Figure 1 (assuming a specific charge of $0.15 \mathrm{~kg}$ per $\mathrm{kW}$ cooling capacity). A further constraint applied to the use of the formula was that the molar mass of the refrigerant must be greater than $42 \mathrm{~g} \mathrm{~mol}^{-1}$. Specifically, for "non-fixed factory-sealed single package units" (essentially portable ACs and humidifiers), an alternative ACL is offered, corresponding to $25 \%$ of the LFL times the room volume, and can be used provided the charge is between $4 \times$ LFL $<m \leq 8 \times$ LFL ( $m$ in $\mathrm{kg}$ ). In addition, the unit must circulate airflow within the room, corresponding to at least four air changes per hour.

It has been widely reported that the ACL formula in IEC 60335-2-40 is restrictive when applying it to common room air conditioning and air-to-air heat pump systems (e.g., Corberan et. al, 2008; Li, 2014; Vonsild, 2012; Zhang et. al., 2013). This is illustrated by the evaluation shown in Figure 1. Here, systems of various capacities with four different efficiency classes from the Eurovent database (Eurovent, 2017) are plotted against charge quantities, adjusted for R290-equivalent by using the liquid densities ratio of R290 to the refrigerant at $45^{\circ} \mathrm{C}$ (GIZ, 2011). ACLs for R290 from the formula are superimposed for four different indoor unit's installation heights, assuming a nominal design load of $150 \mathrm{~W} \mathrm{~m}^{-2}$, which is "average" across Europe (Huang et al., 2018). For R290 to be viable for use across a range of systems and products, the ACL lines would need to be moved to above the data-points so that the R290-charged systems would be able to be installed in most rooms.

Whilst it is in principle possible to cool rooms with multiple systems, there would be a significant cost detriment for products using A3 refrigerants. This demonstrates that current ACLs obstruct the selection of R290 (and other A3s), especially for higher efficiency models; the consequence is even starker for applications with higher loads, i.e., above $150 \mathrm{~W} \mathrm{~m}^{-2}$. This observation is echoed in a recent report on significant barriers to the uptake of flammable refrigerants by the European Commission (DGClima, 2016) and the UNEP TEAP Task Force report (UNEP, 2017). The restrictions seen here highlight the need to reexamine the validity of current approaches and assumptions to reflect practical variability.

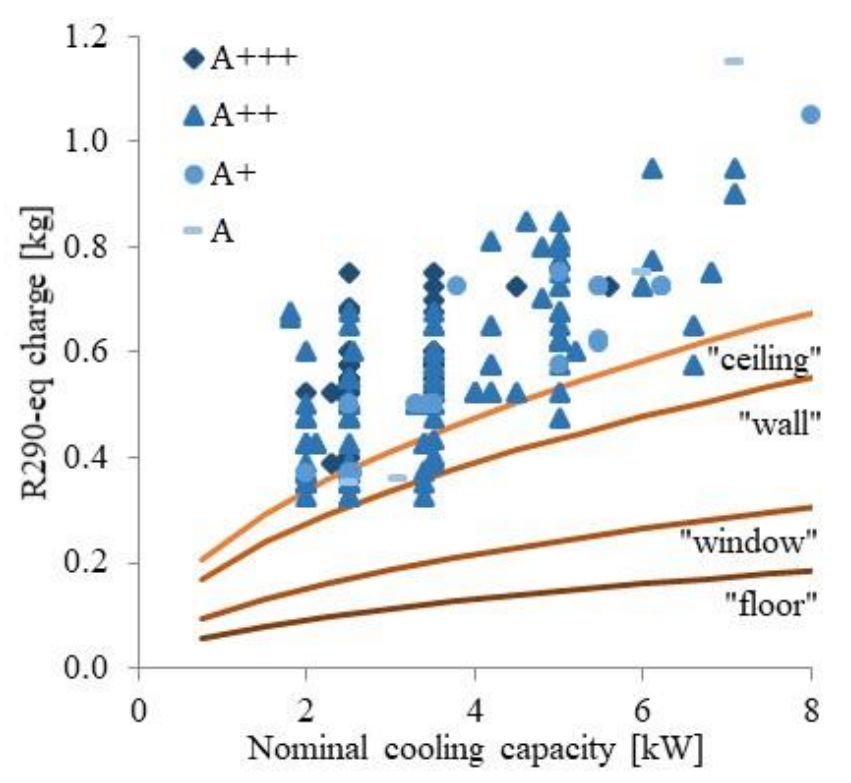

Figure 1: Comparison of RACS charge (converted to R290-eq.) and current allowable charge limits for a $150 \mathrm{~W} \mathrm{~m}^{-2}$ load

Another way of expressing the required charge in relation to AC unit size is with the graph in Figure 2. The four curved lines relate the allowable charge to the room area (depending upon unit type/height) and the two dashed lines plot the expected cooling demand of the room against its floor area, depending upon whether it is "low" or "high" load. The region below the dashed lines indicate the situations where insufficient refrigerant is permitted to achieve the cooling demand.

When applying the ACL formula from IEC 60335-2-40, a variety of assumptions are made. Some of these have been examined within the wider literature that may not be directly related to RACHP systems (for 
example, influence of direction of a release and room air movement), whereas others were originally addressed in some respects by the authors of this formula (Kataoka et al, 2000). It is important to readdress some of these assumptions to help understand and determine whether alternatives could be made, and how they can be integrated into revised CL formulations.

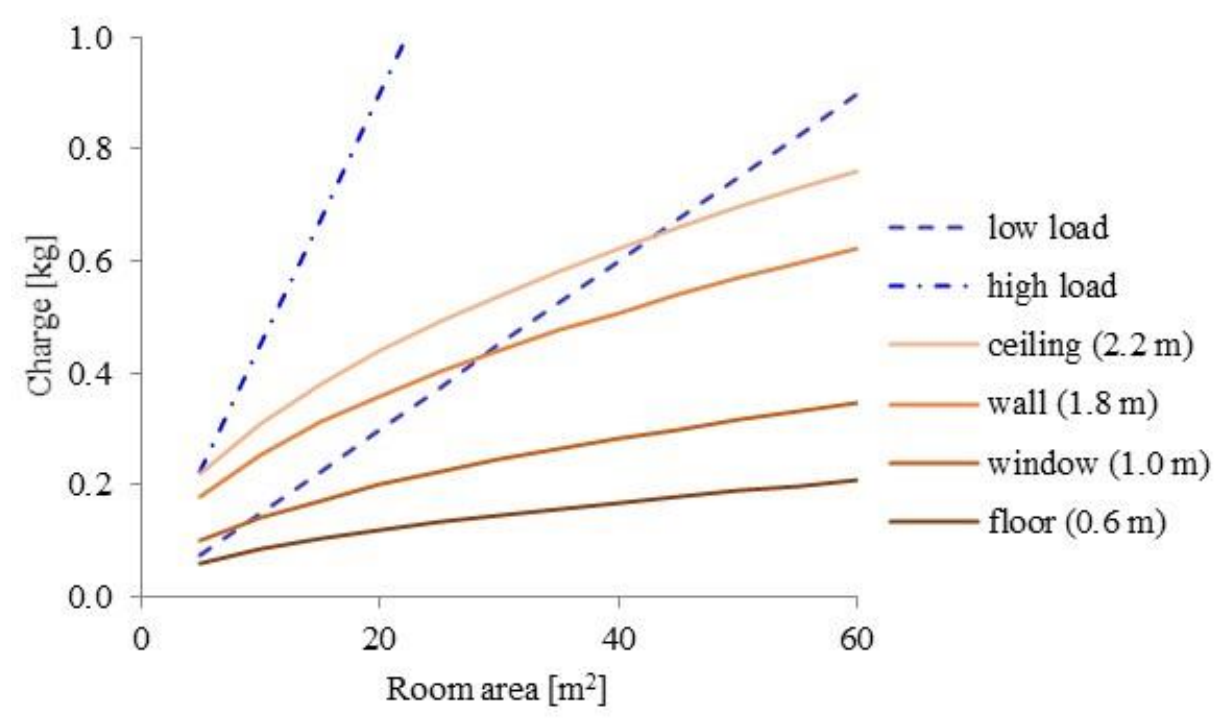

Figure 2: Comparison of required charge for $A 3$ refrigerant AC systems and A3 ACLs according to the various RACHP standards for ceiling, wall, window and floor units; low load $=100 \mathrm{~W} \mathrm{~m}^{-2}$, high load $=300 \mathrm{~W}$ $\mathrm{m}^{-2}$, specific charge $=0.15 \mathrm{~kg} \mathrm{~kW}^{-1}, L F L=40 \mathrm{~g} \mathrm{~m}^{-3}$

\subsection{Limits for "other" applications}

Horizontal/group standards adopt another CL formula intended for "other" applications (which are not covered by IEC 60335-2-40 ACL) which is simply taken as the product of 20\% of the LFL and the room volume within which the system is entirely or partially installed. The $20 \%$ factor is/was assumed to account for the stratification of the leaked refrigerant. This ACL formula can be appropriate for certain circumstances, for example, when applied to a coldroom. However, it may not be appropriate from a perspective of suitability or limiting flammability risk. On one hand, for instance, with a small convenience store it is unlikely to offer sufficient A3 refrigerant charge to satisfy the cooling demand of the system. On the other hand, in the case of a system that is located close to floor level, even a "small" leak could easily result in a substantial flammable volume and thus could be considered higher risk. For these reasons, a more suitable approach to determining ACLs is desired.

\section{Legislative framework}

Most countries/regions have legislation that governs equipment related to potentially flammable and explosive atmospheres. All EU countries have implemented the ATEX (equipment) (2014) and ATEX (workplace) (1999) directives, and in fact almost all other countries subscribe to an equivalent or similar legislative framework. Similarly, these countries adopt the same or comparable "Ex" type" (as defined in the IEC 60079-series of standards) standards for protection of equipment used within areas where flammable gases could be present. It is observed that amongst the various regulations, no CLs are prescribed. Instead, the general approach taken is to ensure that there are no sources of ignition (SOI) within potentially flammable zones. To achieve this, the standard EN and IEC 60079-10-1 specifies a methodology to determine the size of a zone, based on for example, the fluid flammability characteristics, fluid pressure, anticipated largest non-catastrophic leak hole size, ventilation in the area, etc. There exist standards that define requirements for ensuring that electrical or other components do not act as SOIs, which can be used within the assumed flammable zone. 
It is not practical to mandate Ex-type components throughout spaces where small RACHP systems and equipment are typically installed; this would diminish the convenience and relatively low cost of cooling (and heating) systems. However, the approach may be applied in the opposite direction whereby the amount of refrigerant, likely hole size, internal pressure, etc. are limited such that the zone would not extend significantly beyond that of the RACHP equipment where SOIs can be fairly easily eliminated. ${ }^{2}$ In this way, the principles of the various national and regional regulations and standards on controls of explosive atmospheres can be adhered to.

In addition, other protective measures can be applied to RACHP systems, equipment and installation areas to limit the size of the zones. Such measures include additional airflow, extract ventilation, natural ventilation, physical barriers within RACHP housings, etc. These are not currently applicable to HC refrigerants within the RACHP safety standards for systems other than those in machinery rooms.

\section{Possible approaches for revising CLs}

According to published safety standards and literatures (e.g. IEC 60079-series), three broad approaches can be used to establish CLs: "prescriptive", "determination by test" and "risk assessment". The "prescriptive" method is normally adopted in RACHP standards (as in Table 1). Typically, this is where the ACL is calculated from space dimensions, the refrigerant LFL and other characteristics, including airflow and space wall apertures. "Determine by test" can be used when simple calculations are deemed incapable of handling complex situations or are found to yield too small a charge quantity for the application. Such tests can include measurements within the space to demonstrate that concentrations do not exceed some fraction of the refrigerant's LFL. Commensurate with this, tests for determining the total amount of refrigerant that could leak from the system under normal conditions could be performed (e.g., Colbourne et al, 2013). With these test methods, any protective measures (e.g., IEC/ISO, 2014; IEC, 2018; IEC, 2019) may be applied singly or in any combination to provide the most cost-effective approach. "Risk assessment" approach may be adopted, whereby details of the application, environment, protective measures, etc. are accounted for using numerical/quantitative or qualitative methods. Resultant risk values or rankings can then be gauged against acceptability criteria - such as published accident or fatality data (e.g., DCLG, 2014) - to establish whether the proposed design would be deemed suitable or any other protective measures would be needed. This approach is already included in EN 1127-1 (2019) and as a safety standard for refrigerated marine containers using flammable refrigerants (ISO 20854: 2019).

Whilst considering revised CLs, it is important to ensure that they to some extent match the cooling or heating demands of common applications, otherwise the task would be of limited practical use. There are two distinct situations in which the desired charge quantity may be determined, using any one of the above approaches:

i) Systems where the cooling or heating capacity is dictated by the dimensions and characteristics of the room(s) that it serves (e.g. air conditioners and coldrooms), and

ii) Systems where the cooling or heating capacity is broadly independent of the room(s) that it is located within (e.g. display cabinets and hydronic heat pumps).

Situations also exist that encompass both (i) and (ii), such as "indoor" coldrooms with monoblock systems.

Based on industry data (e.g., Hawkins, 2011), direct experience of applying RACHP systems and anticipation of near-term developments in terms of RACHP system charge amounts, estimations can be made on how much refrigerant is needed. For instance, it has been estimated that coldroom systems require about $80 \mathrm{~g}$ of $\mathrm{A} 3$ refrigerant per $\mathrm{m}^{3}$ of room size, whereas window and single split air conditioners normally demand up to about $40 \mathrm{~g} \mathrm{~m}^{-3}$. Multi-split AC requires more, in the order of $100 \mathrm{~g} \mathrm{~m}^{-3}$. Plug-in retail cabinets use around of $50 \mathrm{~g} \mathrm{~m}^{-3}$ and remote cabinets about $70 \mathrm{~g} \mathrm{~m}^{-3}$ - based on convenience store situations. Heat pumps (liquid-to-liquid) - assuming they are installed in typical small utility room - would have about $300 \mathrm{~g}$

\footnotetext{
${ }^{2}$ The exception is for larger capacity systems installed in special machinery rooms where it is assumed that potentially large flammable zones could be created and so appropriate protective measures can be applied to the entire space, such as Ex-type electrical equipment and dedicated ventilation.
} 
$\mathrm{m}^{-3}$ (for space heating applications). Air-to-air type heat pumps are considered as air conditioning systems and the $\mathrm{g} \mathrm{m}^{-3}$ is essentially the same. Nevertheless, such values are highly dependent upon system design and construction, local climate, building insulation and so on. The above values represent the upper end of what would be needed.

A fundamental aspect related to $\mathrm{HC}$ product development is to optimise the charge to achieve as much cooling or heating capacity as possible per unit mass of charge. For integral air conditioning systems, the best available options require about $60 \mathrm{~g} \mathrm{~kW}^{-1}$ or $90 \mathrm{~g} \mathrm{~kW}^{-1}$ for heat pump systems, and for refrigeration systems the required charge is around $150-250 \mathrm{~g}$ per $\mathrm{kW}$ (for chilling and freezing temperatures, respectively).

RACHP system design strategies evolve over time and the charge for a given capacity and temperature levels has tended to reduce correspondingly. In particular, the increased use of flammable refrigerants has led to an acceleration of charge minimisation (IIF-IIR, 2014). On the other hand, with increasing minimum efficiency rules and regulations, there can be a conflicting trend to raise charge quantities (depending upon the optimisation strategy). Also, an increased charge may be more related to covering wider operating conditions than to optimising efficiency. The average charge of ACHPs within the Eurovent database (Eurovent, 2017) varies according to energy label, as indicated in Table 2. On average, for systems with an energy label raised from A to A+++, approximately 50\% more charge is used. Most of the products within the Eurovent database have not been subject to intensive charge minimisation/optimisation (due to them using A1 or A2L refrigerants). Thus, the increased specific charge for higher efficiency models may be relatively greater than what might be expected with charge-optimised systems using class A3 refrigerants.

Table 2: Variation in specific charge with energy label

\begin{tabular}{|c|c|c|c|c|}
\hline Energy label & A & A+ & A++ & A+++ \\
\hline Specific charge $\left[\mathrm{g} \mathrm{kW}^{-1}\right]$ & 130 & $140(+8 \%)$ & $160(+21 \%)$ & $200(+51 \%)$ \\
\hline
\end{tabular}

Applying the UCLs as in Table 1, the expected cooling (or heating) capacities could be estimated. For direct systems the current CLs result in cooling (or heating) capacities in the order of about $8 \mathrm{~kW}$ (under IEC 60335-2-40) for ACHP systems (or $3 \mathrm{~kW}$ for portable AC units) and about $2 \mathrm{~kW}$ for domestic hot water heat pumps. With "other" refrigeration systems (access category a or b, under EN 378), such as with cabinets or coldrooms the upper range of cooling capacity for as single system would be in the order of 6 to $15 \mathrm{~kW}$, depending upon the temperature level. Applied to hotter climates, these capacities would be reduced and even halved in many cases.

\section{Options for establishing larger ACLs}

Across the wider technical literature and within various RACHP and other safety standards, numerous measures are mentioned for the purpose of minimising flammability and other hazards. Table 3 provides a non-exhaustive overview of the various types and examples along with an identification of whether the function of the measure is principally "active" (e.g., operated by electrical power source) or "passive" (e.g., without electrical or external intervention). Brief remarks are also given regarding the effectiveness and necessary reliability of each for reducing the hazard; these are general since the implications can differ according to the type of system, the application and the surrounding circumstances. Any of these measures can be applied individually or in combination with others. 
Table 3: Measures to minimise flammability hazard

\begin{tabular}{|c|c|c|}
\hline Measures & $\begin{array}{l}\text { Active }(\mathrm{A}) / \\
\text { Passive }(\mathrm{P})\end{array}$ & $\begin{array}{l}\text { Remarks on key requirements for } \\
\text { effectiveness/reliability }\end{array}$ \\
\hline $\begin{array}{l}\text { 1. Limiting charge amount by specifying a maximum } \\
\text { charge }\end{array}$ & $\mathrm{P}$ & $\begin{array}{c}\text { Reliant on technician to not overcharge } \\
\text { system }\end{array}$ \\
\hline $\begin{array}{l}\text { 2. Large enough space for dilution by specifying a } \\
\text { minimum room size }\end{array}$ & $\mathrm{P}$ & $\begin{array}{l}\text { Reliant on installer to determine room } \\
\text { size correctly }\end{array}$ \\
\hline $\begin{array}{l}\text { 3. Limiting releasable amount by using particular system } \\
\text { designs or components (e.g., shut-off valves) }\end{array}$ & $\mathrm{A} / \mathrm{P}$ & $\begin{array}{l}\text { Long term tightness of system design } \\
\text { and reliability of components, leading to } \\
\text { smaller leak holes }\end{array}$ \\
\hline $\begin{array}{l}\text { 4. Limit leakage mass flow rate, such as with internal flow } \\
\text { restrictions }\end{array}$ & $\mathrm{A} / \mathrm{P}$ & $\begin{array}{l}\text { Correct functioning of system } \\
\text { components and detection if used }\end{array}$ \\
\hline $\begin{array}{l}\text { 5. Encourage lower leak probability by improving the } \\
\text { design and construction of the system }\end{array}$ & $\mathrm{P}$ & $\begin{array}{l}\text { Technician maintains tightness when } \\
\text { carrying out repairs }\end{array}$ \\
\hline $\begin{array}{l}\text { 6. Dilution of mixture from housing into room through } \\
\text { improved enclosure design }\end{array}$ & $\mathrm{P}$ & $\begin{array}{l}\text { Enclosure construction is not } \\
\text { compromised by occupants }\end{array}$ \\
\hline $\begin{array}{l}\text { 7. Dilution of mixture in room by using unit circulation } \\
\text { airflow }\end{array}$ & A & Unit fan airflow is always available \\
\hline $\begin{array}{l}\text { 8. Dilution of mixture in room by using separate } \\
\text { circulation airflow }\end{array}$ & A & Separate fan is always available \\
\hline $\begin{array}{l}\text { 9. Removal of mixture from occupied room relying on } \\
\text { natural ventilation }\end{array}$ & $\mathrm{P}$ & $\begin{array}{l}\text { Good availability of conditions } \\
\text { (temperature, wind speed, direction) }\end{array}$ \\
\hline $\begin{array}{l}\text { 10. Removal of mixture from occupied room relying on } \\
\text { buoyancy induced exchange }\end{array}$ & $\mathrm{P}$ & $\begin{array}{l}\text { Flow channels and openings remain } \\
\text { unobstructed/interfered with }\end{array}$ \\
\hline $\begin{array}{l}\text { 11. Removal of mixture from occupied room using } \\
\text { mechanical ventilation }\end{array}$ & A & $\begin{array}{l}\text { Fan and detection system always } \\
\text { functioning }\end{array}$ \\
\hline $\begin{array}{l}\text { 12. Removal of mixture from unit enclosure/housing by } \\
\text { relying on natural ventilation }\end{array}$ & $\mathrm{P}$ & $\begin{array}{l}\text { Conditions (temperature, wind speed, } \\
\text { direction) frequently as needed }\end{array}$ \\
\hline $\begin{array}{l}\text { 13. Removal of mixture from unit enclosure/housing by } \\
\text { relying on buoyancy induced exchange }\end{array}$ & $\mathrm{P}$ & Flow channels remain unobstructed \\
\hline $\begin{array}{l}\text { 14. Removal of mixture from unit enclosure/housing by } \\
\text { relying on pressure generated by refrigerant leak }\end{array}$ & $\mathrm{P}$ & $\begin{array}{c}\text { Flow channels remain unobstructed and } \\
\text { enclosure envelope is tight }\end{array}$ \\
\hline $\begin{array}{l}\text { 15. Removal of mixture from unit enclosure/housing using } \\
\text { mechanical ventilation (to the open air) }\end{array}$ & A & $\begin{array}{l}\text { Fan and detection system always } \\
\text { functioning }\end{array}$ \\
\hline $\begin{array}{l}\text { 16. Eliminating SOIs in occupied space by terminating } \\
\text { electrics }\end{array}$ & A & Detection system always functioning \\
\hline $\begin{array}{l}\text { 17. Eliminating SOIs in occupied space by using protected } \\
\text { electrical and other equipment throughout }\end{array}$ & $\mathrm{P}$ & $\begin{array}{l}\text { Integrity of protected electrical/other } \\
\text { equipment maintained }\end{array}$ \\
\hline $\begin{array}{l}\text { 18. Warning personnel within the occupied space by means } \\
\text { of audible/visual alarms and instructions }\end{array}$ & A & $\begin{array}{c}\text { Detection system always functioning } \\
\text { and occupants react as intended to alarm } \\
\text { and have read instructions }\end{array}$ \\
\hline
\end{tabular}

There is an option termed "proof by test" which potentially involves any selected or combination of measures, whereby a leak is simulated from the refrigerant circuit and the concentration at key positions within the room is monitored for the duration of the release and for a period after it ceases. The test is "passed" provided the concentration does not exceed some fraction of the LFL. The upside of this type of safety performance test is that almost any combination of protective measures can be integrated into RACHP equipment and be assessed overall. Another application may be where additional confidence is required to be 
demonstrated with an unusual design of RACHP equipment. Obviously, the success of such tests depends on the validity of assumptions regarding leak hole size and release rate.

Critical to the active measures, there must be some form of indication of a release occurring, i.e., leak detection. There are currently three viable technologies in use: gas detection, ultrasonic leak detection and system parameter-based detection and each have pros and cons, depending upon the type of equipment and installation circumstances.

\section{Considerations to determine charge limits}

A suitable approach then may be to offer several levels of requirements for establishing ACLs. As discussed earlier these requirements may respectively correspond to: "calculation based", "experiment based", "combination" (i.e., calculation based on tests or vice versa) and by risk assessment. Although ACLs may be calculated, this is not necessarily done in isolation since the characteristics of the mitigation measure(s) may also need to be determined in order to validate the charge limit (e.g., minimum airflow rate).

Figure 3 provides an overview. In conjunction with these determination methods, there are two classes of protection: "active" and "passive" (as discussed in Table 3). Similarly, the protective measures may be applied to one or more elements associated with the installation, being the system design and construction (D\&C) itself, the "equipment D\&C" (such as the housing) or the room D\&C. Further, the principal mitigation approach may be to retain as much refrigerant as possible inside the system, dilute the release via internal mixing within the space (enclosure or room) to below LFL, or exhaust the mixture from the enclosure. As with the determination method, one or more of the types of protection, element(s) selected and the mitigation approach can be combined, if necessary.
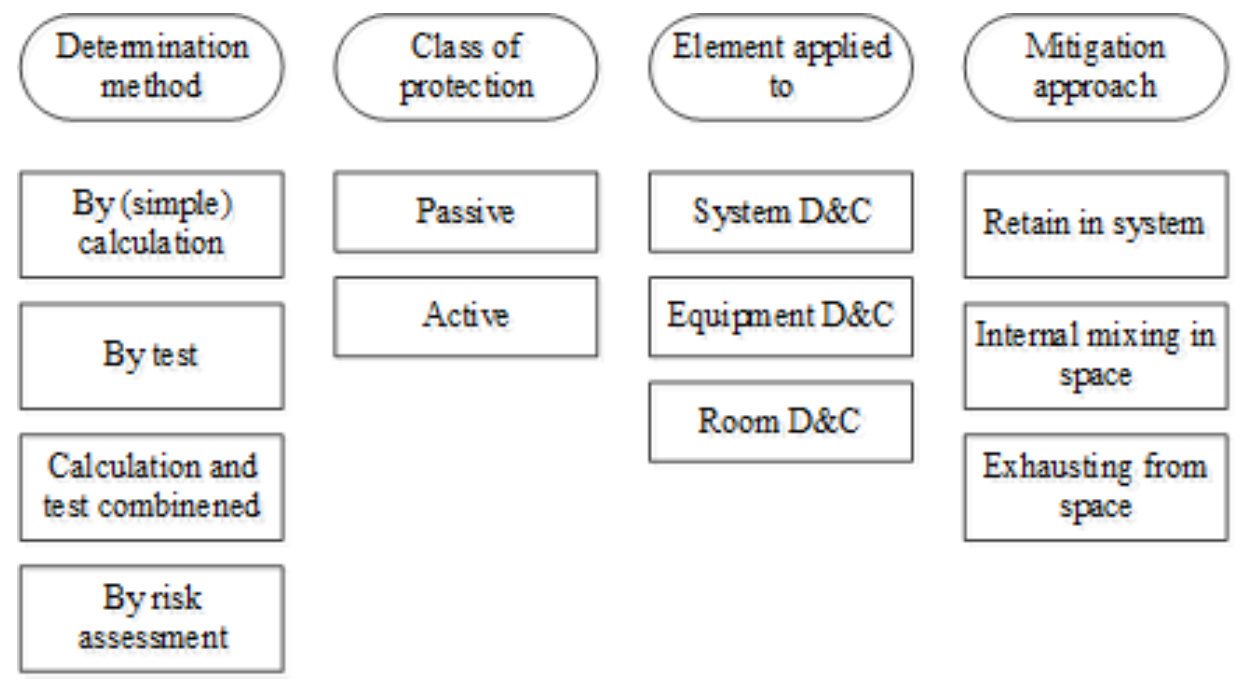

Figure 3: Possible concept elements for addressing CLs

Due to the complexities and variations associated with construction and characteristics of RACHP systems, equipment and rooms within which RACHP equipment are installed, CLs found by calculation only tend to yield smaller numbers. This is primarily because many of the aspects that may help to reduce room floor concentration have to be accounted for in the most pessimistic manner in the calculation.

Referring to Table 1, all of the UCLs presented could be considered as somewhat arbitrary, having no clear origins or rationale. Rather than being seen as a limit to minimise the likelihood of ignition of a release, UCL is arguably used to minimise the intensity of a fire, either due to direct ignition of the refrigerant or - as is more likely - due to an external fire. The fact that there are no such UCLs for non-flammable refrigerants helps support this. In this respect, UCLs may be considered as a function of the heat of combustion (HoC) of the refrigerant and possibly in relation to the volume of the space that the system is installed; $1 \mathrm{~kg}$ of R290 
burning in a $10 \mathrm{~m}^{3}$ space would be substantially more intense than in a $100 \mathrm{~m}^{3}$ volume. Accordingly, if the ACL is already (broadly) a function of space volume, then the upper limits should also be accounted for automatically and need not be specified separately. Otherwise these UCLs imply that once a certain quantity of flammable refrigerant has been released, there should be a radical increase in the risk. Figure 4 provides some results from simulations of R290 in different sized rooms for a range of released mass. Risk of overpressure (determined as the product of maximum overpressure from deflagration on the frequency of each occurrence) (Colbourne and Suen, 2008) is plotted against released mass.

The individual lines show the gradual increase in risk as the quantity of released refrigerant increases and the change of behavioural trend of the individual lines is indicative of the having a flammable layer across the entire floor area. There is a dashed line which corresponds to the risk of a release for an assumed value of say, $10 \% \times \mathrm{LFL} \times$ room volume. This indicates that for a charge relative to the space volume, the risk diminishes as the space volume increases.

Currently, as shown in Table 1, UCLs are specified in the safety standards, of $1.5 \mathrm{~kg}$, regardless of room size and unit height. However, the results suggest otherwise as there is no clear evidence a nominal UCL is necessary. In other words, the boundary between "safe" and "unsafe" is defined by the mass of refrigerant, the unit height $(h)$ and the room size, rather than some specific mass of refrigerant.

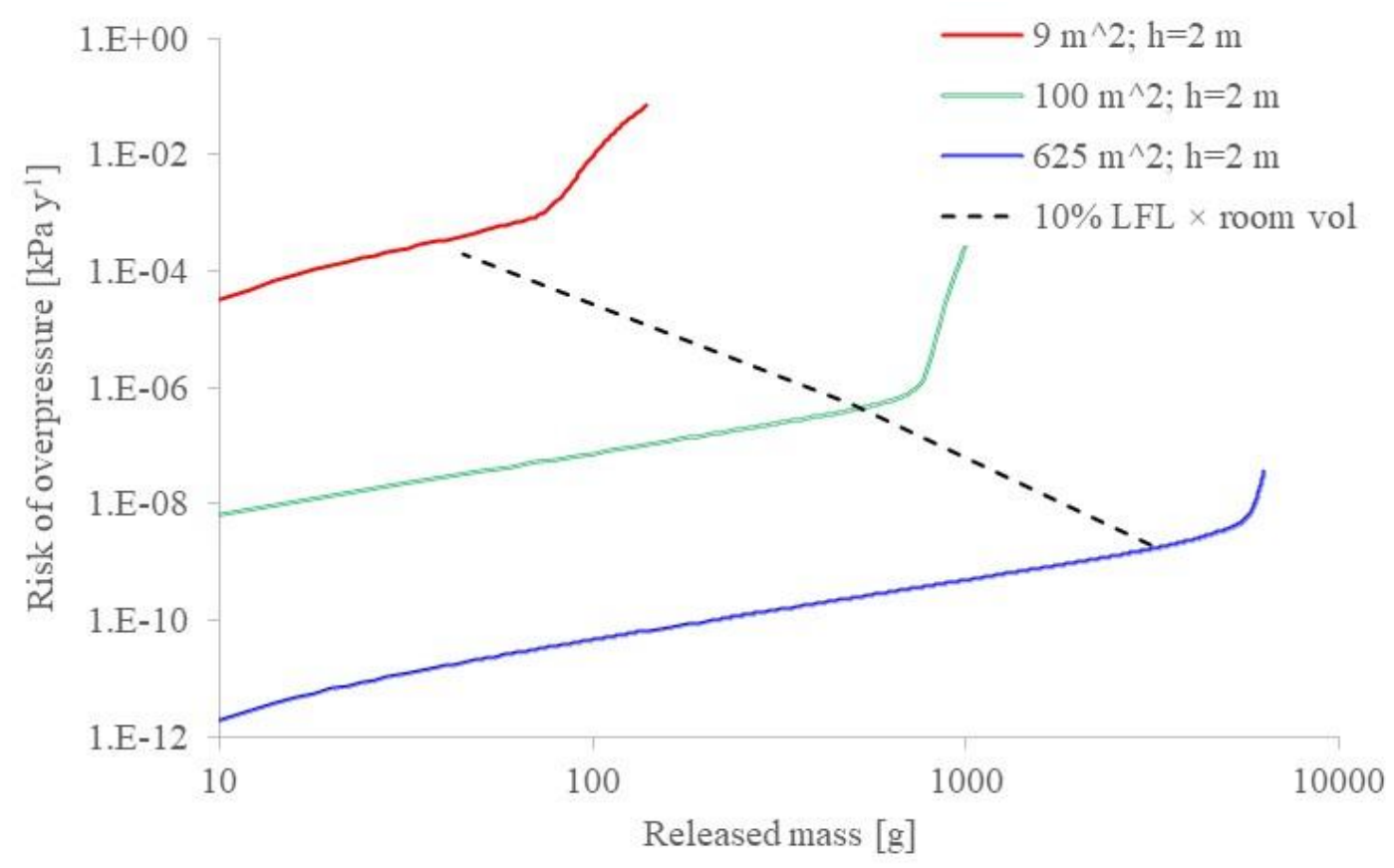

Figure 4: Effect of released R290 mass on risk of overpressure

In general, it can be concluded that for RACHP equipment installed inside and where the amount of refrigerant is proportional to the room size, there should be no UCL, since it is self-limiting by means of the ACL. For systems located in the open air, one may argue that UCL could be applied and this should be proportional to the refrigerants' $\mathrm{HoC}$ as the amount of energy exerted in the event of ignition could eventually cause severe damage and injury. Considering the various flammable refrigerants within ISO 817 (2014), most A3 refrigerants have a similar HoC, whilst A2 and A2L refrigerants' HoCs are broadly similar being about one-fifth of $\mathrm{A} 3$ refrigerants. Based on this, it might be reasonable to apply a UCL to A2s and A2Ls at about five times that being applied to A3 refrigerants.

The competence of practitioners and users, such engineers and technicians, must also be taken into account. Amongst the stakeholders there exists a wide range of technical competence and expertise, therefore, proposed CLs and associated requirements should to some extent be accessible to all levels. Conversely it 
may be argued that if proposed requirements demanded a higher level of technical understanding it could dissuade less competent personnel from using flammable refrigerants unsafely.

\section{Final remarks}

Whilst the various RACHP safety standards essentially cover the same primary systems (i.e., an electricallydriven compression refrigerating circuit), there is a vast diversity in the manner by which A3 refrigerant CLs are dealt with. This is nonsensical and unhelpful, as it appears that there is inconsistent logic and moreover, practitioners need to remember a variety of rules that are to a small or large extent, conflicting. As such, horizontal/group and appliance standards should be revised to reflect a more harmonised and consistent approach to determining CL and these should span all of the horizontal/group and vertical standards.

It is proposed that these CL rules are based on evaluating a given RACHP unit, including its prescribed protective measures and for ACLs:

- A clear and unambiguous calculation method, being a function of room size and RACHP equipment characteristics (such as housings, enclosures and amount of air flow or ventilation) irrespective of the end use;

- A safety performance test (e.g., "surrounding concentration test", similar to that within Annex CC in IEC 60335-2-89) where the refrigerant is released and the floor concentration is measured to ensure it does not exceed some fraction of the LFL), whilst allowing protective measures to function as intended;

- A method for flammability risk assessment, based on anticipated charge, number and characteristics of SOIs, other characteristics of the RACHP unit and some tolerable level of risk against which the calculation result could be gauged, such as the exercise carried out in Colbourne and Suen (2004).

The concept of UCLs should be eliminated for most (indoor) situations as it serves hardly any purpose, except to instil confusion in practitioners. An exception would be for systems located in the open air, where excessive quantities of flammable refrigerant should be avoided.

\section{Acknowledgement}

The authors would like to acknowledge GIZ Proklima of the Deutsche Gesellschaft für Internationale Zusammenarbeit (GIZ) GmbH (https://www.giz.de/fachexpertise/html/61049.html) and the EU LIFE Front project (http://lifefront.eu/) for supporting this work.

\section{References}

ATEX (Equipment) Directive 2014/34/EU of the European Parliament and of the Council of 26 February 2014 on the harmonisation of the laws of the Member States relating to equipment and protective systems intended for use in potentially explosive atmospheres (recast)

ATEX (Workplace) Directive 1999/92/EC of the European Parliament and of the Council of 16 December 1999 on minimum requirements for improving the safety and health protection of workers potentially at risk from explosive atmospheres (15th individual Directive within the meaning of Article 16(1) of Directive 89/391/EEC

Colbourne D., Rajadhyaksha D., Sahu A. 2013. HC-290 as an alternative refrigerant for split air conditioning systems in high ambient temperatures. Proc. IIF-IIR. Compressors 2013: 8th International Conference on Compressors and Coolants, Častá - Papiernička.

Colbourne, D., Espersen, L. 2013. Quantitative risk assessment of R290 in ice cream cabinets. Int. J. Refrig., Vol. 36, Issue 4, pp 1208-1219.

Colbourne, D., Suen, K. O. 2004. Appraising the flammability hazards of hydrocarbon refrigerants using quantitative risk assessment model Part I: modelling approach, Int. J. Refrig. Vol. 27, pp. 774-783.

Colbourne, D., Suen, K. O. 2008, risk analysis of flammable refrigerants, Part 2: Methodology for calculation of risk frequencies and flammable quantities, Proc. 8th IIR Gustav Lorentzen Conf., Copenhagen, Denmark. 
Corberan, J. M., Seguradoa, J., Colbourne, D., Gonzalvez, J. 2008. Review of standards for the use of hydrocarbon refrigerants in $\mathrm{A} / \mathrm{C}$, heat pump and refrigeration equipment. Int. J. Refrigeration, vol. pp748-756.

DCLG, 2014. Fire Statistics: Great Britain April 2012 to March 2013. Department for Communities and Local Government. Office for National Statistics, London, UK.

Deutsche Gesellschaft für Internationale Zusammenarbeit (GIZ). 2011. Operation of split air conditioning systems with hydrocarbon refrigerant. Proklima International, Eschborn, Germany.

DGClima, 2014. National Codes, Standards and Legislation of EU Member States with respect to F-Gas alternatives, Report for European Commission, ED60326/CLIMA.C.2/SER/2014/0019r.

EN 335-2-24: 1992 Household and similar electrical appliances - Safety - Part 2-24: Particular requirements for refrigerating appliances, ice-cream appliances and ice makers.

EN 378-1: 2016. Refrigeration Systems and Heat Pumps - Environmental Requirements - Basic requirements, definitions, classification and selection criteria.

EU 'Blue Guide' on the implementation of EU products rules, 2016, 4933 (2016/C 272/01).

DG Clima. European Commission, 2016. Report from the Commission on barriers posed by codes, standards and legislation to using climate-friendly technologies in the refrigeration, air conditioning, heat pumps and foam sectors. $\operatorname{COM}(2016) 749$ final. Brussels, 30.11.2016.

Eurovent, 2017. https://eurovent.eu/. Last accessed in 2017.

Hawkins, G., 2011. Rules of Thumb - Guidelines for building services. 5th Edition, BG9/2011, BSRIA, Bracknell, UK. HSE, 2001. Reducing risks, protecting people. Health and Safety Executive, HMSO, Norwich, UK.

Huang, B., Martin, P., Hansen, S., Viegand, J., Riviere, P., Asloune, H., et al. Air conditioners and comfort fans, Review of Regulation 206/2012 and 626/2011 Final report. (Research Report) European Commission, DG Energy, 2018.

hydrocarbons21.com/articles/8994/in_reversal_iec_approves_increase_of_charge_limit_for_flammable_refrigerants. Last accessed September 2019.

IEC 60079-10-1: 2015. Explosive atmospheres - Part 10-1: Classification of areas - Explosive gas atmospheres.

IEC 60335-2-24:2010+A1: 2012 Household and similar electrical appliances - Safety - Part 2-24: Particular requirements for refrigerating appliances, ice-cream appliances and ice makers.

IEC 60335-2-40: 2003+A2, 2009. Specification for safety of household and similar electrical appliances. Safety. Particular requirements for electrical heat pumps air-conditioners, and dehumidifiers.

IEC 60335-2-89:2019 Household and similar electrical appliances - Safety - Part 2-89: Particular requirements for commercial refrigerating appliances and ice-makers with an incorporated or remote refrigerant unit or motorcompressor.

IEC Guide 104: 2019 The preparation of safety publications and the use of basic safety publications and group safety publications.

IEC Guide 116: 2018 Guidelines for safety related risk assessment and risk reduction for low voltage equipment IIF-IIR, 2014. 25th Informatory Note on Refrigeration Technologies. Refrigerant charge reduction in refrigeration systems. Paris.

IIF-IIR, 2017. 36th Informatory Note on Refrigeration Technologies. Flammable refrigerants. December 2017, Paris, http://www.iifiir.org/userfiles/file/publications/notes/NoteTech_36_EN_nkyix2fcj7.pdf.

ISO 20854: 2019. Freight Container — Thermal containers — Safety standard for refrigerating systems using flammable refrigerants - Requirements for design and operation.

ISO 5149-1:2014+A1:2015 Refrigerating systems and heat pumps — Safety and environmental requirements.

ISO 817: 2014 Refrigerants — Designation and safety classification.

ISO/IEC Guide 51: 2014 Safety aspects — Guidelines for their inclusion in standards.

Kataoka, O., Yoshizawa, M., Hirakawa, T. 2000. Allowable Charge Calculation Method for Flammable Refrigerants, International Refrigeration and Air Conditioning Conference, Purdue, USA.

Li, T. X., 2014. Indoor leakage test for safety of R-290 split type room air conditioner. Int. J. Refrig., Vol 40, 380-389. 
UNEP, 2018 Report of the Refrigeration, Air Conditioning and Heat Pumps Technical Options Committee, 2018 Assessment. UNEP Environment Programme, Nairobi, Kenya.

UNEP, May 2017. Report of the technology and economic assessment panel Volume 3 Decision XXVIII/4 Task Force Report Safety Standards for Flammable Low Global-Warming-Potential (GWP) Refrigerants. UNEP Environment Programme, Nairobi, Kenya.

Vonsild, 2012 Safety standards for hydrocarbon refrigerants. Proc. 10th IIR-Gustav Lorentzen Conference on Natural Working Fluids (GL2012), Delft, The Netherlands.

WMO, 2014. https://www.who.int/globalchange/publications/quantitative-risk-assessment/en/ Last accessed September 2019.

Zhang, W., Yang, Z., Li, J., Ren, C., Lv, D.,Wang, J., 2013. Research on the flammability hazards of an air conditioner using refrigerant R-290. Int. J. Refrig. 36 (5), 1483-1494.

Zolcer Skačanová, K., Gkizelis, A., Belluomini, D., Battesti, M. Willson, T. 2018. Impact of Standards on Hydrocarbon Refrigerants in Europe - Market research report www.lifefront.eu. 